\title{
Rhino-sino Mucormycosis with Post-COVID-19: A Case Report
}

\author{
Puvaneswari Kanagaraj $^{1}$, Anbueswari Kanagaraj ${ }^{2}$
}

\begin{abstract}
COVID-19 or SARS-CoV-2 infection is known to have an association with a myriad of viral, fungal, and bacterial co-infections. Mucormycosis is a rare angio-invasive fungal infection that has shown a rising trend during COVID-19 infection in India. Mucormycosis is a rapidly progressing fungal infection caused by filamentous fungi in the Mucoraceae family and is frequently seen in diabetic and immune-compromised patients. Mucormycosis is a condition with a fulminant course and a high mortality risk. The early diagnosis and treatment of mucormycosis is very important in terms of prognosis.

Keywords: Amphotericin B, COVID-19, Fungal infection, Mucormycosis, Rhino-orbital mucormycosis, Rhino-sino mucormycosis.

Pondicherry Journal of Nursing (2021): 10.5005/jp-journals-10084-13113
\end{abstract}

\section{BACKGROUND}

Mucormycosis, an angio-invasive disease, ${ }^{1-3}$ is caused by a group of molds called Mucormycetes. These molds live throughout the environment, and it is a rare fungal infection potentially fatal if inadequately treated. ${ }^{4}$ It is often referred to as a black fungus. The estimated prevalence of black fungus is around 70 times higher in India compared with global data. ${ }^{5}$ The incidence of mucormycosis has risen more rapidly in India with COVID-19 second wave compared with the first wave. It was reported as 14,872 cases as of May $28,2021 .^{6}$

\section{Case Description}

\section{Patient History}

Mr X, 48-years-old male, came with complaints of fever, cough, shortness of breath, myalgia, and tiredness for 4 days. On June 2, 2021, the patient was tested for RT-PCR, the result showed COVID-positive, and the computed tomography (CT) severity score was 8 of 25 and identified as diabetic during that time. He got admitted and treated with Inj. Remdesivir, Inj. Pan $40 \mathrm{mg}$, Inj.Lupenox $40 \mathrm{mg}$, Inj.Piptaz4.5 mg, Inj. Methylprednisolone, and Tab. Ivermectin $12 \mathrm{mg}$. Then, Mr X got discharged on June 8, 2021, from the hospital and advised for home quarantine. Meanwhile, since June 7, 2021, he developed on and off nasal obstruction, headache, left-facial pain numbness, and left-tooth numbness for 1 week. On June 14, 2021, with the physical examination in OPD, it was advised to do investigations, like CT sinus scan, biopsy, and other blood investigations. With the help of all diagnostic reports, it was diagnosed as Rhino-sino mucormycosis.

\section{Results of Physical Examination and Laboratory Tests during Admission}

Mr X was conscious and oriented. Oral hygiene was good. Vital signs were stable. Pulse was 84 per minute, and blood pressure was 110 per $70 \mathrm{~mm} \mathrm{Hg}$. Normal vesicular breath sounds heard and no palpable lymph nodes. No other abnormalities were found except left sinus tenderness. The complete blood count was normal
${ }^{1}$ Department of Medical and Surgical Nursing, Narayana Hrudayalaya College of Nursing, Bengaluru, Karnataka, India

${ }^{2}$ Department of Nursing, Government Hospital, Hosur, Tamil Nadu, India

Corresponding Author: Puvaneswari Kanagaraj, Department of Medical and Surgical Nursing, Narayana Hrudayalaya College of Nursing, Bengaluru, Karnataka, India, Phone: +91 9448126938, e-mail: puvaneswariramesh@gmail.com

How to cite this article: Kanagaraj P, Kanagaraj A. Rhino-sino Mucormycosis with Post-COVID-19: A Case Report. Pon J Nurs 2021;14(4):94-96.

Source of support: Nil

Conflict of interest: None

with the red blood cells (5.20 million cells per $\mathrm{cmm}$ ), hemoglobin (15.5 g per $\mathrm{dL}$ ), total count (11900 cells per $\mathrm{mm}^{3}$ ), and platelet count (356000 per $\mathrm{mL}$ ). There was a moderate elevation of erythrocyte sedimentation rate, that is, $30 \mathrm{~mm}$ per hour, PT 14 seconds (INR: 1.2), activated partial thromboplastin time 29 seconds, plasma glucose $102 \mathrm{mg}$ per $\mathrm{dL}$, blood urea $28 \mathrm{mg}$ per $\mathrm{dL}$, and creatinine $0.9 \mathrm{mg}$ per $\mathrm{dL}$.

The CT paranasal sinus scan reported acute sinusitis with subtle left retromaxillary fat stranding. Then, he was taken for functional endoscopic sinus surgery (FESS) under general anesthesia on June 15, 2021. $\mathrm{KOH}$ mount shows no fungal elements seen. Fungal culture shows Rhizopus species grown in culture. Biopsy (medium) reported sinonasal mucosa lined by ciliated pseudo-stratified columnar epithelium with ulceration. Underlying lamina propria shows vague granuloma formation with necrosis comprised of multinucleated giant cells, histiocytes, lymphocytes, and neutrophilic exudates. Amidst few clusters of broad nonseptate fungal hyphae, morphologically suggestive of mucormycosis are seen. Few blood vessels show angioinvasion by fungal hyphae. And, the impression was invasive fungal sinusitis, morphologically suggestive of mucormycosis with angio-invasion and granuloma formation-mucosa from maxillary and ethmoid sinuses.

(c) The Author(s). 2021 Open Access This article is distributed under the terms of the Creative Commons Attribution 4.0 International License (https://creativecommons. org/licenses/by-nc/4.0/), which permits unrestricted use, distribution, and non-commercial reproduction in any medium, provided you give appropriate credit to the original author(s) and the source, provide a link to the Creative Commons license, and indicate if changes were made. The Creative Commons Public Domain Dedication waiver (http://creativecommons.org/publicdomain/zero/1.0/) applies to the data made available in this article, unless otherwise stated. 


\section{Course of Treatment in the Hospital}

On June 16, 2021, after the admission, the patient was treated with a general medicine opinion for glycemic control, and orders were followed. Mr X was treated with Inj. Amphotericin B (AmB) (cumulative dose: $2.30 \mathrm{mg}$ ) along with IV antibiotics, IV antifungal, anti-diabetics, and other supportive measures. Constant monitoring of parameters, like urea, creatinine, and electrolytes, were done. During the treatment, the patient developed few side effects, like chills and decreased appetite, and gastrointestinal symptoms and all were symptomatically managed.

On June 22, 2021, left Caldwell-Luc operation was done. And, the biopsy (medium) report of mucosa from the left maxillary sinus showed fungal sinusitis morphologically consistent with mucormycosis. No conclusive evidence of any osteo-invasion/ angio-invasion in the sections was studied. Fungal culture report shows Rhizopus species grown in culture. $\mathrm{KOH}$ mount shows Aseptate hyaline fungal hyphae seen. Then, the treatment was continued. After June 22, 2021, there was an elevation of urea and creatinine value, and protein was low in the liver function test (Tables 1 and 2). Patient got discharged when symptoms, like nasal obstruction, headache, left-facial pain and numbness, and left-tooth numbness, improved. The follow-up medications (Table 3) were advised for 7 days.

\section{Discussion}

Mucormycosis is an acute and aggressive fungal infection. ${ }^{7}$ The clinical presentations of mucormycosis are classified based on anatomic localization, such as rhino-orbital-cerebral, pulmonary, gastrointestinal, cutaneous, renal, and disseminated mucormycoses. ${ }^{8,9}$ Diabetes mellitus is the most common risk factor for mucormycosis, along with hematological malignancy, chronic kidney disease, solidorgan transplant, postpulmonary tuberculosis, immunosuppressive therapy like steroids, and extensive skin injury. ${ }^{5}$ The occurrence of mucormycosis is variable but usually occurs around third week of onset of symptoms of COVID-19. ${ }^{10}$ Infection portal of entry included surgery and the presence of medical devices, such as catheters or adhesive tapes in healthcare-associated mucormycosis. Rhizopus was the most frequent gene. ${ }^{11}$ Amphotericin $\mathrm{B}(\mathrm{AmB})$ is a crucial agent in the management of serious systemic fungal infections. It has side effects, like nausea, vomiting, rigors, fever, hypertension or hypotension, and nephrotoxicity. ${ }^{12}$ Patients begin treatment within 5 days of diagnosis of mucormycosis, and survival was markedly improved compared to initiation of anti-fungal $\geq 6$ days after diagnosis ( 83 vs. $49 \%$ survival). ${ }^{13}$

In the present case, the patient was a diabetic, but blood glucose was under control. He got admitted for COVID-19 treatment and received immune suppressive therapy for 6 days during admission and continued during quarantine also. He developed

Table 1: Blood biochemistry

\begin{tabular}{lcccccc}
\hline Component & June 20, 2021 & June 23, 2021 & June 24, 2021 & June 25, 2021 & June 27, 2021 & June 28, 2021 \\
\hline Urea (mg/dL) & 17 & 35 & 51 & 67 & 81 & 73 \\
Creatinine (mg/dL) & 0.8 & 1.4 & 2 & 3.4 & 4 & 3.8 \\
Sodium (mmol/L) & 139 & 139 & 134 & 128 & 126 & 135 \\
Potassium (mmol/L) & 3.8 & 2.7 & 4.2 & 3.7 & 3.1 & 3.7 \\
Calcium (mg/dL) & 8.9 & 8.6 & 8.4 & 8.9 & 8.5 & 8.3 \\
Magnesium (mg/dL) & $\mathbf{2 . 4}$ & 1.6 & 1.4 & 1.5 & 2 & 1.8 \\
\hline
\end{tabular}

Table 2: Liver function test

\begin{tabular}{|c|c|c|c|c|c|c|c|c|c|}
\hline Date & $\begin{array}{l}\text { Total bilirubin } \\
(\mathrm{mg} / \mathrm{dL})\end{array}$ & $\begin{array}{l}\text { Direct bilirubin } \\
(\mathrm{mg} / \mathrm{dL})\end{array}$ & $\begin{array}{l}\text { Indirect bilirubin } \\
(\mathrm{mg} / \mathrm{dL})\end{array}$ & $\begin{array}{c}\text { Total } \\
\text { protein }(g / d L)\end{array}$ & $\begin{array}{c}\text { Albumin } \\
\text { (g/dL) }\end{array}$ & $\begin{array}{l}\text { Globulin } \\
\text { (g/dL) }\end{array}$ & $\begin{array}{c}A S T \text { (SGOT) } \\
(U / L)\end{array}$ & $\begin{array}{c}A L T \text { (SGPT) } \\
(U / L)\end{array}$ & $\begin{array}{l}A L P \\
(U / L)\end{array}$ \\
\hline June 27, 2021 & 0.65 & 0.24 & 0.41 & 5 & 3.4 & 1.6 & 16 & 23 & 66 \\
\hline June 28, 2021 & 0.69 & 0.17 & 0.52 & 4.7 & 3.2 & 1.5 & 14 & 18 & 61 \\
\hline
\end{tabular}

Table 3: Medications

\begin{tabular}{lclcc}
\hline Sl. No. & Form of medication & Drug name & Dose & Frequency \\
\hline 1 & Tablet & Faropenem & $200 \mathrm{mg}$ & $1-0-1$ \\
2 & Tablet & Posaconazole & $300 \mathrm{mg}$ & $1-0-0$ \\
3 & Tablet & Pan & $40 \mathrm{mg}$ & $1-0-0$ (BF) \\
4 & Capsule & Vizylac & & $1-0-0$ \\
5 & Tablet & Cetrizine & $10 \mathrm{mg}$ & $0-0-1$ \\
6 & Spray & Solspre Nasal & 2 Puff & $1-1-1$ \\
7 & Tablet & Nexpro-RD & & $1-0-0$ (30 minutes BF) \\
8 & Tablet & Amino rich & & $1-1-1$ \\
9 & Tablet & Prohance-HP & & $1-1-1$ (2 tsp in 1 glass of milk) \\
10 & Syrup & Gaviscon & $10 \mathrm{~mL}$ & $1-1-1$ SOS \\
\hline
\end{tabular}


the symptoms of mucormycosis around third week with COVID-19. Rhizopus was found with a fungal culture. Mr X was treated for mucormycosis within 10 days of symptom development, which gave a better prognosis. The antifungal agent $A m B$ was initiated based on his tolerance. He had an elevation of blood urea and creatinine, which may be a sign of nephro toxicity.

Hence, early diagnosis and timely intervention are essential to improve the quality of life of a patient with mucormycosis.

\section{Nursing Management of $\mathrm{Mr} \mathrm{X}$ with Mucormycosis}

- Provided an atmosphere of respect, openness, trust, and collaboration.

- MrX was very anxious about his condition and prognosis during a pandemic. He was not willing to talk to people and showed crying spells, irritability, etc. Assessed the patient's health perceptions, knowledge, and counseled him to overcome the anxiety.

- Explained the condition of the patient and the needed treatment, like FESS and Caldwell-Luc procedure. Slowly gained the confidence of the patient with rapport, and he cooperated for further treatment.

- Family members were very anxious; with the detailed explanation and proper communication, they could also developed family coping.

- He had insidious onset of dull-aching left-sided pain with a score of 5 of 10. Fowler's position was maintained with the help of the backrest. He was comfortable in the right lateral position with the help of pillows.

- Obtained a strict glycemic control of patient.

- Assessed the patient's intake and output, creatinine levels, and serum potassium levels, since Inj. AmB causes hypokalemia. During the treatment regimen, potassium and creatinine levels were monitored every day. The lowest potassium level during his hospital stay was $2.7 \mathrm{mmol}$ per $\mathrm{L}$, and the highest creatinine level was $4 \mathrm{mg}$ per $\mathrm{dL}$.

- Potassium supplements were given.

- Encouraged Mr X to take adequate fluids orally.

- Adequate hydration was maintained with antifungal treatment.

- Discharge advice was given to the patient. Suggested to do few blood investigations by the seventh day of follow-up.

\section{Conclusion}

Mucormycosis is an aggressive opportunistic fungal infection that has a high incidence in India compared to the world during
COVID-19 pandemic. As the prognosis varies from poor to fair, aggressive medical and surgical management is critical. Excellent communication and an in-depth discussion with the patient and family regarding prognosis are fundamental in caring for these patients.

\section{References}

1. Awal SS, Biswas SS, Awal SK. Rhino-orbital mucormycosis in COVID-19 patients—a new threat? Egypt J Radiol Nucl Med 2021;52(1):152. DOI: 10.1186/s43055-021-00535-9.

2. Karadeniz Uğurlu Ş, Selim S, Kopar A, Songu M. Rhino-orbital mucormycosis: clinical findings and treatment outcomes of four cases. Turk J Ophthalmol 2015;45(4):169-174. DOI: 10.4274/ tjo.82474.

3. Frater JL, Hall GS, Procop GW. Histologic features of zygomycosis: Emphasis on perineural invasion and fungal morphology. Arch Pathol Lab Med 2001;125(3):375-378. DOI: 10.5858/2001-125-0375HFOZ.

4. Available from: http://www.cdc.gov/fungal/diseases/mucormycosis. index.html.

5. Prakash H, Chakrabarti A. Epidemiology of mucormycosis in India. Microorganisms 2021;9(3):523. DOI: 10.3390/microorganisms9030523.

6. Raut A, Huy NT. Rising incidence of mucormycosis in patients with COVID-19: another challenge for India amidst the second wave? Lancet Respir Med 2021;9(8):E77. DOI: 10.1016/S2213-2600(21)00265-4.

7. Bhansali A, Bhadada S, Sharma A, Suresh V, Gupta A, Singh P, et al. Presentation and outcome of rhino-orbital-cerebral mucormycosis in patients with diabetes. Postgrad Med J 2004;80(949):670-674. DOI: 10.1136/pgmj.2003.016030.

8. Roden MM, Zaoutis TE, Buchanan WL, Knudsen TA, Sarkisova TA, Schaufele RL, et al. Epidemiology and outcome of zygomycosis: a review of 929 reported cases. Clin Infect Dis 2005;41(5):634-653. DOI: $10.1086 / 432579$.

9. Jeong W, Keighley C, Wolfe R, Lee WL, Slavin MA, Kong DCM, et al. The epidemiology and clinical manifestations of mucormycosis: a systematic review and meta-analysis of case reports. Clin Microbiol Infect 2019;25(1):26-34. DOI: 10.1016/j.cmi.2018.07.011.

10. MucormycosismanagementinCovid-19.pdf (dghs.gov.in).

11. Rammaert B, Lanternier F, Zahar JR, Dannaoui E, Bougnoux ME, Lecuit M, et al. Healthcare-associated mucormycosis. Clin Infect Dis 2012;54(suppl_1):S44-S54. DOI: 10.1093/cid/cir867.

12. Laniado-Laborín R, Cabrales-Vargas MN. Amphotericin B: side effects and toxicity. Rev Iberoam Micol 2009;26(4):223-227. DOI: 10.1016/ j.riam.2009.06.003.

13. Chamilos G, Lewis RE, Kontoyiannis DP. Delaying amphotericin B-based frontline therapy significantly increases mortality among patients with hematologic malignancy who have zygomycosis. Clin Infect Dis 2008;47(4):503-509. DOI: 10.1086/590004. 